\title{
AS REGIÕES DE PLANEJAMENTO DE MINAS GERAIS SOB A ÓTICA DO DESENVOLVIMENTO RURAL SUSTENTÁVEL: UMA ABORDAGEM TEÓRICO-METODOLÓGICA ${ }^{1}$
}

\author{
The regions of planning of Minas Gerais under the \\ sustainable rural development vision: A theory \\ Approach-methodology
}

Envio 28.07.08 / Aceite 24.10.09

Edson Arlindo Silva ${ }^{2}$

Nádia Campos Pereira ${ }^{3}$

José Roberto Pereira ${ }^{4}$

Denise Carneiro dos Reis Bernardo ${ }^{5}$

\section{Resumo}

O estudo revelou uma tipologia dos municípios mineiros a partir de suas principais características sociais, econômicas e institucionais de desenvolvimento rural sustentável. Com esse fim, foram aplicados dois métodos estatísticos multivariados (componentes principais e classificação por cluster), utilizando 20 indicadores, divididos em seis dimensões, definidas pelo Ministério do Desenvolvimento Agrário, na forma de diretrizes para o desenvolvimento rural sustentável, são elas: Diversidades sociais e regionais; Direitos e qualidade de vida; Conhecimentos e saberes; Organização social e participação política; Organização econômica e mercados e Produção, consumo e sustentabilidade. Os indicadores foram

\footnotetext{
${ }^{1}$ Artigo publicado no VI International PENSA Conference "Sustainable Agri-food and Bioenergy Chains/Networks Economics and Management" sob o título de "Sustainable rural development in Minas Gerais state: a tipology from techniques of multivariated analysis and cluster". In Oct., 24-26th, 2007, School of Business and Economics of Ribeirão Preto - University of São Paulo. Ribeirão Preto - São Paulo - Brasil

${ }^{2}$ Professor da Universidade Federal de Viçosa, Campus Rio Paranaíba. Doutorando em Administração pela Universidade Federal de Lavras. e-mail: edsonsilva@ufv.br

${ }^{3}$ Mestranda em Administração pela Universidade Federal de Lavras.

${ }^{4}$ Professor do Departamento de Administração e Economia da Universidade Federal de Lavras e Doutor em Sociologia.

${ }^{5}$ Professora da Universidade Federal de São João Del Rei e Doutoranda em Administração pela UFLA.
} 
selecionados a partir de diversas fontes de dados, para os 853 municípios do estado de Minas Gerais, e os resultados mostraram que é possível agrupar os municípios mineiros em quatro regiões relativamente homogêneas: municípios em condições muito favoráveis de desenvolvimento rural sustentável; municípios em condições favoráveis de desenvolvimento rural sustentável; municípios em condições pouco favoráveis de desenvolvimento rural sustentável e municípios em condições desfavoráveis de desenvolvimento rural sustentável.

Palavras-chave: Tipologia; Desenvolvimento Rural Sustentável; Análise Multivariada; Cluster.

\begin{abstract}
This study aimed to built a typology of the communities in Minas Gerais from their social, economic and institutional characteristics of sustainable rural development. We applied two multivariate statistical methods (principal components and cluster) using 20 variables divided in six dimensions defined by the Ministry of Rural Development as directives of rural sustainable development. The six directives are: Regional and Social Diversities; Rights and Quality of Life; Knowledge; Social Organization and Political Participation; Economic Organization and Markets; Production and Sustainability. The variables were collected from many sources for the 853 communities of Minas Gerais. The results show that it is possible to aggregate the communities in four groups relatively homogeneous: communities in really favorable conditions of sustainable development; communities in favorable conditions of sustainable development; communities with little conditions of sustainable development communities no favorable conditions of sustainable development.
\end{abstract}

Keywords: Typology; communities in Minas Gerais; rural sustainable development. Multivariate Analysis; Cluster.

\title{
1 Cenários e características da área estudada
}

O Brasil rural, bem como o estado de Minas Gerais, comporta uma multiplicidade de ambientes físicos, recursos naturais, agroecossistemas, sistemas agrários, etnias, culturas, relações sociais, padrões tecnológicos, formas de organização social e política, linguagens, simbologias, demonstrando que o espaço rural brasileiro não é uniforme, mas diverso, plural e heterogêneo.

Apesar dessa diversidade, o espaço rural brasileiro ainda é fortemente marcado por uma estrutura fundiária desigual, com tendência histórica à concentração da propriedade da terra, que provoca exclusão social e pobreza estrutural, constituindo-se em forte empecilho ao desenvolvimento rural (LAMOUNIER, 1994; BARRACLOUGH, 1998).

Historicamente, tendo como base as análises e interpretações contidas nos estudos de Zhang e Fan (2006), Kageyama e Leone (1999), Vitorino et al. (2004), essa heterogeneidade tem se traduzido na convivência, de um lado, da agricultura patronal, que reproduz, no país, um modelo embasado na monocultura e no latifúndio, gerando degradação ambiental, exploração do trabalho agrícola, exclusão social e concentração da terra e da renda. De outro lado, encontra-se a agricultura familiar que, apesar de sofrer perdas de renda e ter dificuldades de acesso aos benefícios das políticas públicas, procura estabelecer sistemas de produção focados 
na biodiversidade, na valorização do trabalho familiar, na produção de alimentos destinados à segurança alimentar (MALUF, 2001).

Nesse contexto, verificou-se, ao longo dos últimos anos, um aumento da competitividade no agronegócio, por meio da especialização produtiva, da adoção de tecnologias de ponta e da produção em larga escala, o que têm sido fundamental para a obtenção de saldos no comércio exterior e para ajudar a equilibrar as contas da economia do país. No entanto, nas regiões ocupadas predominantemente pelo agronegócio, observa-se também uma fragilidade das redes formadas por micro e pequenas empresas, detentoras de inegáveis potencialidades, para revitalizar as dinâmicas econômicas locais. Tais circunstâncias contribuíram para o surgimento de uma nova proposta de desenvolvimento rural, com enfoque nas diferentes dimensões da sustentabilidade econômica, social, política, cultural, ambiental e territorial, como é o caso das evidências empíricas encontradas no estado de Minas Gerais, foco deste estudo.

Assim, o rural tem um papel central na construção de um novo projeto de sociedade, sendo visto como um espaço que deve diversificar e multiplicar a pluralidade, tanto dos sistemas de produção - não os uniformizando - quanto das atividades rurais não-agrícolas; viabilizar novas estratégias de conservação ambientais compatíveis com a produção sustentável; promover e estimular dinâmicas de inclusão social e promoção da igualdade; e gerar alternativas tecnológicas que favoreçam a disseminação da autonomia relativa de produtores familiares, como propõe Helfand (1999).

O conjunto dessas características, somado a outros fatores da dinâmica macroeconômica, aponta na direção de um rural que assegure a existência da diversidade dos agroecossistemas, com valorização das atividades agroecológicas, orgânicas e agroflorestais; a integração de diferentes setores econômicos; o resgate e a valorização das formas tradicionais de manifestação e produção cultural e dos saberes locais acumulados e repassados de geração a geração; o fortalecimento das formas de organização comunitária e a valorização e recriação das identidades coletivas (KAGEYAMA e LEONE, 1999; BUAINAIN e REZENDE, 1995). Destaca-se que, para definir e implementar uma estratégia voltada à construção de um espaço rural sustentável que fortaleça as formas de produção familiar e tradicional, faz-se necessária uma profunda reformulação do padrão de desenvolvimento rural. A implementação desse projeto requer um processo de planejamento de médio e longo prazo, com a definição de novas estratégias, novas diretrizes e novos instrumentos de política pública, além de promover a rearticulação do setor agrícola com os demais setores da economia.

Contudo, esse desafio implica ainda na construção de novas institucionalidades e arranjos institucionais que permitam ações mais articuladas das políticas públicas, integrando as iniciativas do Estado em suas diferentes esferas das organizações da sociedade civil e das empresas privadas, mesmo reconhecendo-se que, nas esferas estaduais e municipais, há poucas iniciativas neste sentido. Sendo assim, o objetivo deste estudo foi o de apresentar uma proposta que respaldasse a construção empírica de uma tipologia dos municípios mineiros a partir de suas principais características sociais, econômicas, jurídicas e institucionais de desenvolvimento rural sustentável. As peculiaridades do tema implicam na seleção de indicadores adequados aos objetivos do estudo, que podem ou não ser adequados a outros contextos, configurando estas e outras questões metodológicas apresentadas neste trabalho.

A proposta desta tipologia é a de apresentar uma base territorial de grupos relativamente homogêneos de municípios quanto a um conjunto de variáveis. Para cumprir o objetivo proposto, os indicadores foram selecionados a fim de contemplar as seis esferas estratégicas definidas pelo Ministério do Desenvolvimento Agrário no Plano Nacional de Desenvolvimento Rural Sustentável, são elas: Diversidades sociais e regionais; Direitos e qualidade de vida; 
Conhecimentos e saberes; Organização social e participação política; Organização econômica e mercados e Produção, consumo e sustentabilidade, como serão discutidas nas seções que se seguem.

\section{Desenvolvimento rural sustentável: o caso mineiro repercutido no cenário brasileiro}

A noção de desenvolvimento sustentável origina-se a partir das discussões feitas pelo "Clube de Roma", em 1948, sendo identificado, na época, um aumento das atividades industriais em várias partes do mundo, aceleração do processo de degradação ambiental, poluição, crescimento desorganizado dos grandes centros urbanos e expansão da fronteira agrícola via desmatamento e inobservância de limites de reservas legais (CAVALCANTI, 1995).

Com a constatação de distúrbios ambientais em quase todas as partes do mundo e com o crescimento acelerado das atividades industriais comprometendo consideravelmente a qualidade de vida, foi realizada, em 1972, na cidade de Estolcomo, Suécia, uma conferência para tratar das questões ambientais, objetivando promover debates em torno da problemática ambiental, tendo por base expectativas em torno da transição de uma relação de deterioração dos recursos naturais para uma relação de desenvolvimento sustentável. A conferência de Estocolmo, dentre várias temáticas discutidas, chamou a atenção do mundo para a conscientização e preservação do meio ambiente. Tratava-se na constituição de uma proposta ampla e duradoura para colocar a questão sobre meio ambiente na agenda mundial. Essa proposta visava a criar as condições necessárias para minimizar os efeitos negativos advindos do processo de industrialização via desenvolvimento econômico.

Para Silva (2000 apud ZEE-MMA, 2002), a idéia de desenvolvimento sustentável surge como alternativa para reequilibrar a dicotomia entre preservação do meio ambiente e crescimento econômico, já que

\footnotetext{
preconizado, inicialmente, na agenda 21, o desenvolvimento sustentável demanda um novo processo de exploração dos recursos naturais e apropriação do território orientado pela premissa fundamental da valorização humana, levando em conta a sustentabilidade ecológica, social e econômica. Conceitualmente, o desenvolvimento sustentável depende de maior competitividade e eficiência econômica, da melhoria das condições de vida da população e do respeito ao meio ambiente para que as diferentes regiões cresçam de maneira integrada (ZEE-MMA, 2002, p. 18).
}

Assim, o que se percebeu a partir da conferência de Estocolmo foi um movimento de direcionamento de ações públicas e privadas em torno das mazelas ambientais. Este cenário preocupante chamou a atenção de políticos, organizações sociais e ambientais, empresários, movimentos sindicais, organizações religiosas, dentre outras, que começaram a se mobilizar para suprir as carências encontradas em um universo ecológico de extrema preocupação.

Nesse contexto, até recentemente, as reflexões acerca das questões sociais, econômicas, jurídicas, institucionais e, principalmente, ambientais relacionadas à agricultura e urbanização eram pouco consideradas no cenário político-social e econômico. Contudo, pode-se dizer que as atuais preocupações estão buscando voltar-se para uma reflexão que tenta integrar as visões compartimentadas em um processo de reflexão global, entendendo o urbano não apenas como fruto de sua própria evolução, mas como resultante também do processo de 
desenvolvimento do espaço rural (CARVALHO, 2001; HELFAND, 1999). Daí a necessidade em pensar crescimento econômico atrelado à preservação ambiental, tendo em vista a noção de sustentabilidade.

Em contrapartida, observa-se que o processo de desenvolvimento econômico acabou por gerar uma intensa heterogeneidade estrutural das economias latino-americanas e brasileira, resultante do fato de que os países em desenvolvimento, em sua transição para o capitalismo industrial, fizeram-no de forma duplamente retardatária, ou seja, primeiro o fizeram após os países centrais terem atingido processos avançados de industrialização. Segundo, principalmente porque o fizeram após o capitalismo superar a etapa do capitalismo concorrencial e com crescente internacionalização (DELGADO e CARDOSO JR., 2001).

Enquanto países que primeiro se desenvolveram puderam promover mais cedo e mais lentamente a transformação de sua agricultura, enquanto os países em desenvolvimento passaram por processo diverso. Praticavam agricultura atrasada e, mesmo no segmento exportador, a agricultura não guardava identidade de nível tecnológico com a dos países desenvolvidos. Nos países desenvolvidos, a desigualdade estrutural também estava presente, porém bem menos acentuada, mesmo para aqueles países europeus menos desenvolvidos. Isso porque o processo de industrialização e modernização se deu de forma mais estável e, portanto, o processo de urbanização se deu de maneira menos abrupta do que aqueles verificados no mundo subdesenvolvido (CARVALHO, 2001).

As discussões feitas por Rezende (2000), Bresser Pereira (1998) e Veiga (2004) revelam que, no Brasil, o atraso da agricultura até o decênio de 1960 era o traço marcante nesse setor. No que se refere ao produto para a exportação, algum grau de modernização se manifestava para que se pudesse manter a competitividade no mercado externo. Em relação ao setor produtor para o mercado interno, a produção se manifesta com baixo grau tecnológico, crescendo vegetativamente pela expansão da área plantada, o que permitia um crescimento do contingente populacional, urbano e rural, as taxas muito mais elevadas do que aquelas verificadas em países desenvolvidos.

Estudos, realizados entre os decênios de 1980 e 1990 do século passado no Brasil, permitem analisar que a manutenção do atraso dessa agricultura agravava cada vez mais a sobrevivência do imenso contingente de sua população rural. No caso brasileiro, pelo menos desde a década de 1930, isso engendrou um grande fluxo de imigração, o chamado êxodo rural, em direção às zonas urbanas mais densamente povoadas, como Minas Gerais, Rio de Janeiro e, notadamente, São Paulo, mas também áreas rurais mais distantes e de mais fácil acesso a terra, como Paraná e Mato Grosso. Contudo, a partir do decênio de 1960, essa agricultura notadamente voltada para o segmento exportador ou para a produção de insumos para a transformação industrial acelera seu processo de modernização. Agora, por razões diferentes, ou seja, por elevar sobremodo a produtividade do trabalho, gerava um acréscimo àquele fluxo migratório, engrossando as fileiras do êxodo rural em direção às cidades (GRAZIANO DA SILVA, 1993; KAGEYAMA e LEONE, 1999). Assim, a industrialização e urbanização que vão se processando são incapazes de absorverem o excedente que está sendo liberado tanto pela manutenção do atraso quanto pela modernização da agricultura.

Por outro lado, seu segmento exportador é reflexo das vicissitudes da demanda externa, tendo altas e baixas decorrentes de flutuações econômicas cíclicas e de eventos naturais como secas, excesso de chuvas, geadas entre as regiões. O acentuado desnível entre o crescimento de renda gerada na agricultura e o ritmo de crescimento urbano-industrial, bem como dos referidos desníveis de salários imprime movimentos mais abruptos às flutuações de demanda de alimentos, gerando pressões sobre o nível de preços e crise de abastecimento. De forma 
resumida, são os seguintes problemas gerados pela agricultura nos países subdesenvolvidos e que afetam o mundo urbano.

Para Graziano da Silva (1993), no segmento moderno - insumos para a indústria e exportáveis - a modernização elevou a produtividade do trabalho gerado e, ao mesmo tempo, contribuiu para a expulsão de mão de obra e transformando o restante de seus trabalhadores na situação dos "boias-frias" que vivem produtivamente no ambiente rural, mas socialmente no ambiente urbano. Essa modernização, contudo, fez pouco em relação aos rendimentos físicos da terra, que continuam baixos. O uso indiscriminado de agrotóxicos, por sua vez, tem contribuído fortemente para a degradação ambiental das águas, muitas delas usadas para o abastecimento humano.

No segmento produtor de alimentos simples, Maluf (2001) observa que não é a modernização que expulsa sua população, mas sim a manutenção do atraso, pela baixa produtividade e pelo crescimento da miséria. Seu constante deslocamento espacial tem gerado uma série de problemas ao abastecimento urbano: as distâncias cada vez maiores implicam em maiores custos de transporte e crescentes dificuldades de armazenagem e distribuição. Esses impactos se multiplicam, gerando aumentos de custos e de preços.

Entretanto, para melhor compreender as discussões feitas anteriormente em torno dos aspectos que norteiam a agricultura mineira e brasileira e as políticas públicas a elas direcionadas, sob a orientação das diretrizes ligadas à sustentabilidade, torna-se necessário entender a relação entre Estado e Sociedade sob as óticas de dois aspectos importantes, a saber: "desenvolvimento econômico" e "desenvolvimento político", já que ambos encontram-se intimamente ligados em uma mesma dinâmica, neste caso específico, com vistas ao desenvolvimento rural sustentável. Tais discussões serão apresentadas no item seguinte.

\section{Desenvolvimento econômico e político: ambiguidades e complementaridades}

A maioria dos recentes estudos referentes às "Formas de Gestão Pública Brasileira e Políticas Públicas" consideram Huntington um autor influente nessas áreas. Nesse contexto, o histórico apresentado por Huntington (1969) em relação aos acontecimentos políticos, sociais e econômicos revela um cenário de contradições e perspectivas entre as principais questões levantadas pelo autor, quais sejam, desenvolvimento econômico e desenvolvimento político; modernização e participação política; corrupção e o excesso de leis.

Sendo assim, o autor inicia a sua construção textual por meio das distinções existentes entre os graus de atuação governamental e aponta a confusão existente entre a esfera pública e a esfera privada, tendo, muitas vezes, como consequência, a emergência da corrupção e desvios de conduta. A partir deste momento, a tese defendida por este autor se desenvolve pela análise referente à desarmonia existente entre as mudanças socioeconômicas e o desenvolvimento e/ ou fortalecimento das instituições políticas, acarretando, necessariamente, o declínio dessas instituições.

Portanto, tendo em vista que a definição de uma instituição política é fruto de aspectos e características como a estrutura burocrática, organizadas por partidos políticos e participação popular, o que se pode observar na realidade política da América Latina é uma situação de fragmentação das instituições políticas decorrentes, na maioria das vezes, da ausência ou existência de pouco poder, ou seja, ausência ou pouca autoridade para fazer com que as instituições políticas se tornem mais eficientes e que consigam efetivar o seu papel primordial na 
sociedade, qual seja, o zelo pelo bem público, aplicando investimentos tanto na esfera urbana como na rural (BRESSER PEREIRA, 1998; VEIGA, 2004; BARRACLOUG, 1998; BUAINAIM, 1997).

Mas, dentro destecontexto de frustrações, fragmentações edescrençascomasinstituições políticas latino-americanas, Huntington (1969) salienta que a saída para os constantes declínios e crises das instituições políticas em países em desenvolvimento deverá, necessariamente, passar pelo processo de desenvolvimento urbano, agroindustrial, industrial, educacional e de comunicação de massa, o que poderá acarretar em uma melhor conscientização, demanda e aumento da participação popular na definição das políticas públicas a serem geradas (VEIGA, 2004).

Nesse sentido, para que as instituições políticas existam, torna-se necessário estabelecer vínculos de interesses comuns entre os participantes de uma mesma sociedade ou grupo de pessoas, visando a legitimar as instituições. Havendo esta compatibilidade de interesses, fica clara a existência de normas padronizadas de comportamentos ou estabelecimento de valores morais que tendem a organizar as instituições e as pessoas que delas fazem parte, o que seria possível sem o exercício pleno da autoridade.

No debate entre os tipos de desenvolvimento político e econômico, Huntigton (1969) analisou que o econômico marca o avanço de todo processo produtivo e geração de riquezas. Este tipo de desenvolvimento leva a sociedade a experimentar alguns fenômenos que tendem a modernizar tanto o aparato sociopolítico existente em uma determinada localidade como a produtividade e infraestrutura (educação, informação, dentre outros). Há também a mobilização de grupos sociais que buscam certas demandas, como a melhoria de vida e de salários, podendo acarretar frustrações frente às oportunidades existentes e as participações políticas.

O desenvolvimento político, mais precisamente da participação política, é feito em um cenário institucional de baixa institucionalização, acarretando o declínio institucional e tendo como consequências a instabilidade política e dificuldades em se governar, bem como criar as bases necessárias com vistas à elaboração e implementação de políticas públicas voltadas aos mais diversos segmentos produtivos da sociedade brasileira.

Nesse caso, as análises feitas por Bresser Pereira (1998), Lamounier (1994), Vitorino et al. (2004), Huntington (1969) e De Janvry (1983), resguardadas as suas especificidades e focos de estudo, servem de base analítica para evidenciar que o desenvolvimento econômico gerou as bases necessárias para aniquilar os sistemas políticos tradicionais (monarquia, império e república oligárquica), contribuindo de forma significativa para as mudanças institucionais necessárias ocorridas em muitos países ditos desenvolvidos e que ainda não chegou de forma efetiva na maioria dos países da América Latina.

Sendo assim, a saída mais viável está em institucionalizar a participação para haver desenvolvimento político-econômico, ou seja, promover a existência de mecanismos institucionais que atendam às demandas sociais, entre tantas, o desenvolvimento rural sustentável das regiões mais diversas de Minas Gerais e do Brasil.

\section{O espaço rural pensado sob a ótica das diretrizes da sustentabilidade}

Recentemente o Conselho Nacional de Desenvolvimento Rural Sustentável do Ministério de Desenvolvimento Agrário (CONDRAF/MDA) construiu um Plano Nacional de Desenvolvimento Rural Sustentável que servirá de referência para as políticas públicas e para 
a sociedade, bem como para a construção de espaços de concentração social que promovam a sustentabilidade das atividades econômicas, a preservação ambiental e a justiça social. Nesse cenário de expectativas e contradições, emergem discussões em torno das discrepâncias existentes entre as principais regiões que constituem o estado de Minas Gerais, vistas neste trabalho como parte integrante do debate teórico nacional e local aqui exposto.

Contudo, pretendeu-se introduzir, de forma geral, as principais correntes teóricas que tratam da temática "desenvolvimento rural sustentável" como meio de ampliar as análises aqui propostas, no sentido de criar modelos teórico-metodológicos que permitam realizar um estudo comparativo entre o local (Minas Gerais) e o global (Brasil), tendo em vista as evidências empíricas a serem analisadas e expostas em um momento posterior. Assim, tendo em vista o contexto atual direcionado às políticas públicas canalizadas no meio rural, é possível afirmar que o nível de desigualdades existentes na sociedade rural brasileira coloca o país distante de padrões aceitáveis. Para Buainain e Rezende (1995), um consenso entre sujeitos sociais, pesquisadores e estudiosos do meio rural brasileiro estabeleceu que o ponto essencial de uma estratégia de definição ou redefinição do desenvolvimento para as áreas rurais do país deve ser o combate às desigualdades, por meio da criação de oportunidades de trabalho, de renda, de políticas públicas de promoção da igualdade de gênero, raça e etnia. Não se desconhece a importância de políticas compensatórias, necessárias em determinadas circunstâncias, porém estas, em vários momentos, mostraram-se ineficientes e incapazes de tirar as populações pauperizadas e discriminadas da condição de exclusão social em que se encontram (BUAINAIN e REZENDE, 1995; LEITE, 2001).

Porém, estudiosos da área rural, como Kageyama e Leone (1999), Leite (2001) e Graziano da Silva (1993), consideram que a erradicação das desigualdades deve ser o maior objetivo da sociedade rural brasileira, estendida, simultaneamente, para o âmbito urbano. Nesse sentido, não se deve esperar que o crescimento econômico por si só vá resolver a questão das desigualdades. Ao contrário, é preciso inverter essa lógica perversa, transformando essa erradicação em um instrumento que promova o crescimento e o desenvolvimento sustentável. Assim, torna-se indispensável a adoção de políticas públicas que estimulem a população excluída a ter acesso aos bens e serviços essenciais, além de garantir o acesso a um trabalho produtivo e demais recursos econômicos, capaz de assegurar cidadania e superar as diversas desigualdades sociais da população. Dessa forma, este contexto analítico-reflexivo, até então discutido, revela um conjunto de fatores socioeconômicos em que a superação das desigualdades e das injustiças sociais deve ter como ponto primordial o compromisso ético e político de combater a pobreza e a miséria, além de um especial cuidado com a temática ambiental. Nesse caso, as organizações e os movimentos sociais de agricultores rurais e familiares, bem como as entidades de apoio a este segmento, devem desenvolver ações que procurem superar as desigualdades, especialmente as de gênero, regionalidade, culturais, raça e etnia.

De acordo com recentes estudos voltados à percepção macro do cenário políticoeconômico, observa-se que, para além da inflação e do crescimento do Produto Interno Bruto, existem fatores estruturais, como as relações de propriedade da terra e do capital, as relações de trabalho, a dinâmica do setor produtivo e o caráter do Estado, que determinam os padrões de apropriação e distribuição da renda e da riqueza e de conformação das desigualdades (LEITE e MEDEIROS, 2004). Neste caso, é precisamente sobre esses fatores que devem incidir as políticas públicas de caráter redistributivo com vistas à viabilização do desenvolvimento rural sustentável, que constitui a base para a materialização de todos os demais objetivos econômicos e sociais deste segmento da sociedade, e torná-lo compatível com a melhoria das condições de vida e de trabalho da maioria da população do país, bem como garantir que 
também os trabalhadores rurais de todos os gêneros se beneficiem dessa redistribuição e que seja garantido às populações tradicionais o usufruto das terras a que têm direito, como previstos na Constituição Federal do Brasil.

Porém, esse cenário revela que um projeto que pretenda combater as desigualdades não pode abrir mão da participação efetiva do Estado, o qual deverá manter estruturas consistentes e instituições públicas capazes de enfrentar os desafios já delineados em diversos diagnósticos sobre as origens e causas das desigualdades no meio rural (REZENDE, 2003; VEIGA, 2004). Sendo assim, é possível constatar que o Brasil rural apresenta características sociais e regionais bem diferenciadas, conformando contextos e realidades de extrema riqueza e complexidade. Um dos principais pressupostos acerca do espaço rural brasileiro concebe-o na sua diversidade e pluralidade, e não como um espaço homogêneo e uniforme (FREY, 2000; BRESSER PEREIRA, 1998; DELGADO, 2000). Do ponto de vista de sua formação social, observase que esta composição do rural brasileiro é fruto de um somatório de trajetórias históricas que se entrecruzaram no processo de ocupação dos territórios rurais no país (LAMOUNIER, 1994; LEITE, 2001).

Segundo as análises históricas feitas por Helfand e Rezende (2001) em relação à evolução da agricultura brasileira, pode-se afirmar que as dimensões continentais do território nacional impõem também uma pluralidade de ambientes ecológicos que conferem ao espaço rural uma profunda diversidade regional. Essas diferenças estão relacionadas, em certa medida, à variedade de ambientes naturais onde se desenvolvem as atividades econômicas rurais. No entanto, é preciso ressaltar que essa diversidade regional também se refere às políticas públicas que favorecem o desenvolvimento de certas regiões em detrimento de outras, e isso pode até ocorrer no interior de uma mesma região. Nesse sentido, constata-se que as diversidades sociais e regionais não devem ser vistas como fatores limitadores do processo de desenvolvimento, mas como potencializadores e dinamizadores da implementação de um projeto de desenvolvimento sustentável para o Brasil rural. O reconhecimento dessas diversidades sociais e regionais na formação do espaço rural brasileiro, bem como a não omissão de responsabilidades em relação a essa problemática, cumpre um papel fundamental na definição das políticas públicas, na medida em que as ações voltadas para a construção do desenvolvimento sustentável precisam estar balizadas pela existência dessas pluralidades. Em seguida, apresentar-se-ão os procedimentos metodológicos e as técnicas de pesquisa que fundamentaram as discussões e os resultados do estudo em evidência.

\section{Procedimentos metodológicos e técnicas de pesquisa}

Neste trabalho, foram selecionados 21 indicadores, subdivididos em seis dimensões, as quais possuem como referência as diretrizes do Plano Nacional de Desenvolvimento Rural Sustentável, desenvolvido pelo Conselho Nacional de Desenvolvimento Rural Sustentável do Ministério de Desenvolvimento Agrário (CONDRAF/MDA), são elas: Diversidades sociais e regionais; Direitos e qualidade de vida; Conhecimentos e saberes; Organização social e participação política; Organização econômica e mercados e Produção, consumo e sustentabilidade. Os indicadores selecionados referem-se aos 853 municípios de Minas Gerais, sendo, portanto, o município a unidade de análise deste trabalho.

Todos os indicadores foram padronizados através de sua transformação em número índice, a fim de facilitar a análise, a comparação e o agrupamento dos dados. Segundo Hair et al. (2005), um problema enfrentado por todas as medidas de distância que utilizam dados não-padronizados são as inconsistências entre soluções de agrupamentos quando a escala das 
variáveis é mudada. É importante destacar que o pesquisador deve estar atento ao impacto que a escala pode ter sobre a solução final da análise. Para Hair et al. (2005), a padronização gera uma série de benefícios, tais como: a facilidade de comparação de variáveis quando elas estão na mesma escala e a igualdade nos valores padronizados quando apenas a escala muda. Portanto, variáveis padronizadas eliminam os efeitos devido a diferenças de escala não apenas ao longo das variáveis, mas também para a mesma variável (HAIR et al., 2005).

A seguir, serão descritos os indicadores selecionados que foram submetidos à análises utilizando o programa estatístico Statistical Package for Social Science (SPSS) versão 12.0. Inicialmente foram realizadas análises de frequência dos dados através de estatísticas descritivas (média, desvio padrão, mínimo e máximo) e a matriz de correlação dos dados. Em seguida, foram empregadas as técnicas de análise multivariada por componentes principais e cluster, as quais serão apresentadas detalhadamente nas sessões seguintes.

\subsection{Indicadores selecionados}

As dimensões e indicadores selecionados são apresentados resumidamente na Tabela 1.

\begin{tabular}{|c|c|}
\hline Dimensão & Indicador \\
\hline $\begin{array}{l}\text { 1. Dimensão Diversidades Regionais } \\
\text { Sociais }\end{array}$ & $\begin{array}{l}\text { 1. Área Total de Plantios Florestais } \\
\text { 2. Área de Lavouras Permanentes } \\
\text { e. Área de Lavouras Temporárias } \\
\text { 4. Área Utilizada com Pastagens } \\
\text { 5. Áreas Inundadas } \\
\text { 6. Índice de Concentração Fundiária }\end{array}$ \\
\hline 2. Dimensão Direitos e Qualidade de Vida & $\begin{array}{l}\text { 7. Áreas de Unidades de Proteção Integral } \\
\text { 8. ICMS Ecológico de Áreas de Conservação } \\
\text { 9. Coeficiente de agricultores familiares } \\
\text { 10. ICMS de Produção de Alimentos }\end{array}$ \\
\hline 3. Dimensão Conhecimentos e Saberes & $\begin{array}{l}\text { 11. Escola Agrotécnica Federal } \\
\text { 12. Unidades da Empresa de Assistência Técnica e } \\
\text { Extensão Rural do Estado de Minas Gerais (EMATER) } \\
\text { 13. Serviço Nacional de Aprendizagem Rural (SENAR) } \\
\text { 14. Unidades da Empresa de Pesquisa Agropecuária de } \\
\text { Minas Gerais (EPAMIG) }\end{array}$ \\
\hline $\begin{array}{l}\text { 4. Dimensão Organização } \\
\text { Participação Política }\end{array}$ & $\begin{array}{l}\text { e 15. Gestão do Desenvolvimento Rural } \\
\text { 16. Gestão Ambiental Municipal }\end{array}$ \\
\hline $\begin{array}{l}\text { 5. Dimensão Organização Econômica } \\
\text { Mercados }\end{array}$ & $\begin{array}{l}\text { e 17. Pessoal Ocupado na Agropecuária } \\
\text { 18. Número de cooperativas de crédito rural }\end{array}$ \\
\hline $\begin{array}{l}\text { 6. Dimensão Produção, Consumo } \\
\text { Sustentabilidade }\end{array}$ & $\begin{array}{l}\text { e 20. Índice do Setor Agropecuário } \\
\text { 21. Nível Tecnológico Agropecuário }\end{array}$ \\
\hline
\end{tabular}

Fonte: Elaborado pelos autores, 2006/2007.

\subsubsection{Dimensão de diversidades regionais e sociais}

Essa dimensão está relacionada à ocupação do território rural do país sob o ponto de vista da formação regional e da formação social. Essa dimensão buscou representar a diversidade e pluralidade que conferem ao espaço rural brasileiro um ambiente de extrema complexidade e riqueza natural. Nessa dimensão, os indicadores foram agrupados em duas categorias, representando as diversidades regionais e sociais. No contexto deste trabalho, estes indicadores 
serão considerados não como fatores limitadores, mas como fatores potencializadores e dinamizadores do desenvolvimento rural sustentável dos municípios mineiros.

As diversidades regionais são representadas pelos indicadores: Área Total de Plantios Florestais, Área de Lavouras Permanentes, Área de Lavouras Temporárias, Área Utilizada com Pastagens e Áreas Inundadas. Do ponto de vista da diversidade regional, é evidente que existe uma intensa diversidade de ambientes naturais onde se desenvolvem as atividades econômicas rurais. A diversidade social é representada pelo Índice de Concentração Fundiária que, do ponto de vista da formação social, representa o processo de ocupação dos territórios rurais no país, fruto de trajetórias históricas que conferiram ao ambiente rural brasileiro uma composição heterogênea; contudo, em muitos casos, concentrada e desigual. Este indicador representa o grau de desigualdade rural dos municípios. O cálculo do índice é baseado no índice de Gini, que é uma técnica estatística usada para verificar a distribuição estatística de qualquer distribuição amostral. Nessa pesquisa, a referência é a concentração e desigualdade dos estabelecimentos agropecuários.

\subsubsection{Dimensão de direitos e qualidade de vida}

Segundo o CONDRAF/MDA, a dimensão de Direitos e Qualidade de vida está relacionada aos direitos fundamentais da pessoa humana, tais como: o acesso à cidadania, à dignidade, ao pluralismo político, a terra, à água, à segurança e soberania alimentar, à justiça e à segurança pública, à saúde, à educação contextualizada, à moradia, à informação e comunicação, enfim, o acesso aos direitos para toda a população.

Assim, a fim de se alcançar o desenvolvimento rural sustentável, segundo as diretrizes do ZEE-MG (2007), é imprescindível um conjunto articulado de políticas de acesso e preservação dos recursos naturais, bem como de melhorias das condições socioeconômicas de agricultores familiares e das populações tradicionais através de mecanismos de apoio financeiro e de garantia da produção. Os indicadores nessa dimensão foram agrupados em dois grupos que representam as questões relacionadas à preservação de recursos naturais e agricultura familiar. A fim de representar as questões relacionadas à preservação de recursos naturais, foram selecionados os indicadores Áreas de Unidades de Proteção Integral e ICMS ecológico. Compreendem as Unidades de Proteção Integral as seguintes categorias de unidade de conservação: estações ecológicas, reservas biológicas, parques nacionais, monumento natural e refúgio da vida silvestre. A fonte dos dados é a Secretaria Estadual do Meio Ambiente e Desenvolvimento Sustentável (SEMAD). O ICMS-Ecológico é um dos critérios de distribuição da parcela da arrecadação do Imposto sobre Operações Relativas à Circulação de Mercadorias e sobre Prestações de Serviços de Transporte Interestadual e Intermunicipal e de Comunicação (ICMS), pertencente aos municípios, de que trata o inciso II do parágrafo único do art. 158 da Constituição Federal, conforme estabelece a Lei Estadual n.ำ 13.803 de 27/12/2000 (Lei Robin Hood). Este indicador expressa a existência no município de unidades de conservação e a qualidade física dessas áreas, considerando planos de manejo, infraestrutura, entorno protegido, estrutura de proteção e fiscalização, conforme deliberação normativa do Conselho Estadual de Política Ambiental (COPAM).

Os indicadores Coeficiente de Agricultores Familiares e ICMS, referentes à Produção de Alimentos, representam as questões relacionadas aos agricultores familiares. O primeiro caracteriza a agricultura familiar no estado e representa a proporção entre o número total de agricultores familiares do município em relação ao número total do estado. Entende-se a agricultura familiar como aquela que se efetiva através da unidade familiar, com o objetivo 
primeiro de satisfação imediata das necessidades de subsistência da família e da reprodução dessa unidade. O segundo caracteriza as ações que envolvem investimentos voltados à melhoria de condições socioeconômicas de agricultores familiares através de incentivos à produção e comercialização. Este indicador representa um dos critérios de distribuição da arrecadação do Imposto sobre Operações Relativas à Circulação de Mercadorias e sobre Prestações de Serviços de Transporte Interestadual e Intermunicipal e de Comunicação (ICMS) referente à produção de alimentos. Justifica-se seu uso para mensurar e analisar o número de agricultores familiares devido ao potencial de movimentação econômica decorrente do número relativo de famílias produzindo, gerando renda e consumindo no local. Isso pode se tornar fator importante para uma dinâmica econômica mais endógena. Os dados básicos foram obtidos a partir das informações divulgadas pela Fundação João Pinheiro (FJP), Lei Robin Hood, quarto trimestre de 2004.

\subsubsection{Dimensão de conhecimentos e saberes}

Essa dimensão, segundo o CONDRAF/MDA, representa as diversas formas tradicionais de manifestação e produção cultural e dos saberes locais acumulados e repassados de geração em geração e, dessa forma, desempenham um papel estratégico na construção de um modelo de desenvolvimento rural sustentável. Assim, os indicadores selecionados nessa dimensão representam as Instituições de Pesquisa, Experimentação, Extensão Rural e Assistência Técnica.

\subsubsection{Dimensão de organização social e participação política}

A dimensão Organização Social e Participação Política é composta pelos indicadores Gestão do Desenvolvimento Rural e Gestão Ambiental Municipal e objetivam representar a participação social na definição, implementação, monitoramento e avaliação das políticas públicas em Minas Gerais (CONDRAF/MDA). Ainda de acordo com este conselho, essa dimensão representa a garantia de espaços para atuação política dos atores sociais nas políticas públicas, bem como de transparência e eficácia da gestão social do desenvolvimento, dependem de um estímulo contínuo de ações voltadas para o desenvolvimento de capacidades de negociação, de regulação, de articulação e de complementação das iniciativas locais com as ações do Estado, das organizações sociais, dos empresários e com os mercados. Após a Constituição Federal de 1988, verifica-se uma grande expansão de conselhos municipais e estaduais com o objetivo de criar canais de participação dos diferentes atores sociais envolvidos na definição e implementação de políticas públicas em diferentes setores.

O indicador Gestão do Desenvolvimento Rural representa o nível de participação e eficiência nas ações de fomento ao desenvolvimento rural. O indicador Gestão do Desenvolvimento Rural indica a presença ou ausência de Conselhos Municipais de Desenvolvimento Rural Sustentável (CMDRS) e/ou de Plano Municipal de Desenvolvimento Rural Sustentável (PMDRS). Os conselhos são fóruns formais e legais de gestão social que têm como objetivo a discussão, proposição, negociação e gestão de propostas de desenvolvimento rural sustentável nos municípios. Já o PMDRS é um documento norteador das ações a serem executadas, visando ao desenvolvimento rural do município. Nele estão incluídas ações para atender as demandas locais e apoiar, sobretudo, o fortalecimento da agricultura familiar. O plano consolida redes solidárias de cooperação que ajudem a articular o capital social necessário para estabelecer processos sustentáveis de desenvolvimento. 
O indicador Gestão Ambiental Municipal tem como objetivo identificar a existência de estrutura formal voltada para a gestão ambiental. A construção desse indicador se deu com base na existência de departamento (ou similar) de meio ambiente, Secretaria de Meio Ambiente, Conselho de Meio Ambiente, Fundo de Meio Ambiente, Consórcio Intermunicipal na área ambiental e participação em Comitê de Bacia Hidrográfica.

\subsubsection{Dimensão de organização econômica e mercados}

Esta dimensão é representada pelas características de ocupação econômica e incentivos às atividades agropecuárias. Um dos aspectos importantes da organização econômica da produção, segundo o CONDRAF/MDA, é o acesso de agricultores e das populações tradicionais aos mercados, processo que cria oportunidades de trabalho e auxilia na melhoria da renda. Além disso, é imprescindível a atuação de associações e cooperativas, com recursos adequados e serviços técnicos de apoio e fortalecimento da livre organização de agricultores familiares, pescadores artesanais e extrativistas, populações tradicionais, capazes de proporcionar a inserção qualificada desses segmentos nos mercados. A ocupação econômica é representada pelo acesso de agricultores e das populações tradicionais aos mercados - seja através de garantia da comercialização da produção, de apoio à infraestrutura de beneficiamento, agroindustrialização ou comercialização da produção - processo que cria oportunidades de trabalho e auxilia na melhoria da renda. Assim, o indicador selecionado foi o Pessoal Ocupado na Agropecuária, o qual representa o número de pessoas empregadas no setor formal agropecuário em 31 de dezembro de 2003, conforme os registros da Relação Anual de Informações Sociais (RAIS), do Ministério do Trabalho.

Os indicadores que representam os incentivos à atividade agropecuária são o Número de Cooperativas de Crédito Rural e os Gastos per Capita com Promoção às Atividades na Agropecuária como mecanismos de apoio e fortalecimento e inserção qualificada dos diversos segmentos de mercado rural. Os Gastos per Capita objetivam a promoção e o desenvolvimento das atividades agropecuárias. As cooperativas de crédito rural têm como objetivo principal oferecer recursos financeiros a fim de estimular os investimentos rurais, incluindo o armazenamento, beneficiamento e industrialização de produtos agropecuários, quando efetuado pelo produtor na sua propriedade rural, por suas cooperativas ou por pessoas físicas ou jurídicas equiparadas aos produtores. Além disso, visam a favorecer o oportuno e adequado custeio da produção e a comercialização de produtos agropecuários, a fortalecer o setor rural, notadamente no que se refere a pequenos e médios produtores. Os dados foram obtidos pelo Sebrae em parceria com a Fundação João Pinheiro, por meio do projeto denominado "Caminhos para o Desenvolvimento". Os gastos per capita com promoção às atividades na agropecuária representam os gastos orçamentários apresentados nas prestações de conta realizados nas subfunções Promoção da Produção Vegetal, Promoção da Produção Animal, Defesa Sanitária Vegetal, Defesa Sanitária Animal, Abastecimento, Extensão Rural e Irrigação. O somatório desses valores foi deflacionado através do IGP-DI e dividido pelo total da população. As fontes dos dados foram o Tribunal de Contas do estado de Minas Gerais e o Índice Mineiro de Responsabilidade Social, elaborado pela Fundação João Pinheiro.

\subsubsection{Dimensão de produção, consumo e sustentabilidade}

Esta dimensão, segundo o CONDRAF/MDA, representa os processos de modernização que há décadas vêm obedecendo a uma concepção de modernização tecnológica que busca 
aumentar não somente o valor da produção, mas, principalmente, à produtividade física da terra e à produtividade do trabalho por meio de tecnologias que, cada vez mais, substituem o trabalho humano pelo emprego de máquinas, equipamentos e insumos químicos. Compõem esta dimensão o Valor Adicionado do Setor Agropecuário e o indicador do Nível Tecnológico Agropecuário. O valor adicionado do setor agropecuário corresponde, conforme conceituação do Departamento de Contas Nacionais do IBGE, ao valor da produção da atividade agropecuária (lavoura permanente, lavoura temporária, pecuária, horticultura, extrativa vegetal, silvicultura, investimentos em formação de matas plantadas e lavouras permanentes, pesca, indústria rural, produção particular da pessoa residente no estabelecimento rural e serviços auxiliares da agropecuária) menos o consumo intermediário (não computados os impostos). O indicador Nível Tecnológico Agropecuário representa o processo de modernização tecnológica da produção agropecuária dos municípios em relação ao Estado, utilizando como referência o rendimento médio da cultura do milho. Selecionou-se a produtividade desta cultura como proxy do nível tecnológico dada a sua presença na quase totalidade dos municípios mineiros.

A interpretação do indicador se desenvolveu da seguinte maneira: quanto maior a produtividade do milho, maior a probabilidade de adoção de padrões tecnológicos mais sofisticados em outras culturas. Se a produtividade do milho for baixa, a probabilidade de serem baixas as produtividades de outras atividades é alta. O cálculo do índice foi feito mediante os seguintes critérios: a produtividade média do milho no período 2000 a 2004 - com peso de $70 \%$ - e da taxa geométrica de crescimento (TGC) da produtividade desta cultura no período de 1998 a 2004, com peso de 30\%. A fonte dos dados é o Instituto Brasileiro de Geografia e Estatística (IBGE) e a Produção Agrícola Municipal, 2000 a 2004.

\subsection{O Método dos componentes principais}

A análise fatorial é um nome genérico que denota uma classe de processos utilizados essencialmente para a redução e sumarização dos dados. Uma vez assumido que a análise fatorial é uma técnica adequada para analisar os dados, é preciso selecionar o método mais apropriado ao conjunto de informações (MALHOTRA, 2001).

O procedimento metodológico adotado neste trabalho foi o dos componentes principais, o qual leva em consideração a variância total nos dados. Ainda segundo Malhotra (2001), recomenda-se essa técnica quando a preocupação maior é determinar o número mínimo de fatores que respondem pela máxima variância nos dados. Diferentemente de outras técnicas, como a regressão múltipla ou a análise discriminante, o método dos componentes principais analisa a interdependência das variáveis que são simultaneamente consideradas, cada uma relacionada com todas as outras. Alguns dos métodos estatísticos multivariados para modelar a dependência entre variáveis são: análise de regressão múltipla, análise de correspondência múltipla e análise discriminante. Para modelar a interdependência dos dados, tem-se: análise fatorial, análise de agrupamento, análise de correlação canônica, análise de componentes principais e alguns métodos não-paramétricos.

A Análise de Componentes Principais foi desenvolvida inicialmente por Pearson em 1901. A Teoria foi reformulada por Hottling, em 1933, o qual considerou " $n$ " variáveis obtidas de uma população que, por sua vez, precisavam ser redimensionadas. A interpretação dos resultados dependia da diminuição do número de variáveis, mantendo um elevado grau de explicação. Dessa forma, os componentes principais foram desenvolvidos a fim de se descobrir se o processo estava sob controle (FALKENSTEIN e HANWECK, 1997). 
O método de classificação escolhido neste trabalho foi o Método de Ward que, segundo Pereira (2004), é um dos métodos hierárquicos que apresenta melhores desempenhos. Os procedimentos hierárquicos envolvem a construção de uma hierarquia de uma estrutura do tipo árvore. A junção de agrupamentos existentes é, geralmente, representada pelo dendograma ou diagrama em árvore (HAIR et al., 2005).

\section{Resultados e discussões}

Os resultados apresentados a seguir buscaram identificar e agrupar municípios os mais semelhantes possíveis, por meio de um grupo de indicadores selecionados. Inicialmente são apresentados os resultados das análises das estatísticas descritivas média, desvio padrão, mínimo e máximo. Além disso, é apresentada a matriz de correlação dos dados. Em seguida, são apresentados os resultados da análise multivariada por componentes principais e, posteriormente, os resultados da classificação dos municípios (JOHNSON e WICHERN, 1992). Todos os indicadores foram transformados em índices de 0 a 1 para facilitar a análise e comparação dos dados. Os valores em moeda $(R \$)$ foram deflacionados pelo deflator IPCA, conforme informações contidas nas descrições de cada indicador.

Com o objetivo de avaliar a fatorabilidade dos dados e a estimativa do número de componentes, os itens da escala foram submetidos à análise dos Componentes Principais. Analisando-se a matriz de correlação entre as variáveis, observaram-se valores de correlações altos, contudo, os valores foram predominantemente baixos, ou seja, inferiores a 0,30 , indicando ser muito provável a existência de mais de um fator.

O índice Kaiser-Meyer-Olkin compara as magnitudes dos coeficientes de correlação observados com as magnitudes dos coeficientes de correlação parcial. Pequenos valores da estatística KMO indicam que as correlações entre pares de variáveis não podem ser explicadas por outras variáveis, e que a análise fatorial pode ser inapropriada (MALHOTRA, 2001). Segundo este mesmo autor, resultados superiores a 0,50 indicam que a análise fatorial é apropriada. Obteve-se um índice KMO de 0,73, considerado bom para explicar a variabilidade dos dados.

O teste de esfericidade de Barlett é um teste usado para examinar a hipótese de que as variáveis não sejam correlacionadas na população. Ou seja, a matriz de correlação é uma matriz identidade, na qual cada variável se correlaciona perfeitamente com ela própria, mas não se correlaciona com as demais (MALHOTRA, 2001). Os resultados para este teste indicam que a hipótese nula de que a matriz de correlação seja uma matriz identidade foi rejeitada pelo teste de Barlett, uma vez que a estatística qui-quadrado aproximada é 5252,68 e estatisticamente significativa ao nível de 0,05. Quanto mais próximo esse valor for de zero, melhor será a adequação da análise fatorial para o conjunto de dados.

O coeficiente Alfa de Cronbach tem a finalidade de mensurar a consistência interna das variáveis, ou seja, o nível de confiabilidade das variáveis selecionadas. Segundo Hair Jr. et al. (2005), o ideal é que a seja maior que 0,60 . Os resultados da análise indicam a igual a 0,62, ou seja, as variáveis atendem as especificações de confiabilidade dos dados.

O método de rotação utilizado neste trabalho foi o Varimax, uma vez que minimiza o número de variáveis com altas cargas sobre um fator, reforçando a interpretabilidade dos dados. A determinação do número de fatores neste trabalho se deu com base na percentagem de variância. Conforme Aaker et al. (2001), é possível determinar a significância estatística de cada eigenvalue e reter apenas aqueles fatores estatisticamente significantes por meio do critério do teste de significância. É importante ressaltar que, dependendo do tamanho da amostra (principalmente acima de 200, que é o caso deste trabalho), muitos fatores podem apresentar 
alta significância, dificultando, assim, a escolha dos fatores. Malhotra (2001) recomenda que os fatores extraídos respondam no mínimo a $60 \%$ da variância.

Os resultados da Tabela 2 indicam uma estrutura empírica com sete componentes que explicam, em conjunto, 62,93\% dos indicadores selecionados. Esses sete componentes geraram as classificações da dimensão geral, ou seja, a união das seis dimensões estratégicas específicas ao desenvolvimento rural sustentável, denominada, neste trabalho, como Índice de Desenvolvimento Rural Sustentável (IDRS). A justificativa para partir da análise fatorial e não das variáveis originais é que ela pode funcionar como um "filtro" da informação bruta, conservando apenas o que ela tem de mais importante em sua estrutura (KAGEYAMA e LEONI, 1999).

Tabela 2 - Variância total explicada

\begin{tabular}{|c|c|c|c|c|c|c|c|c|c|}
\hline \multirow[t]{3}{*}{ Componente } & \multicolumn{3}{|c|}{ Eigenvalues iniciais } & \multicolumn{3}{|c|}{$\begin{array}{l}\text { Somas extraídas das } \\
\text { cargas ao quadrado }\end{array}$} & \multicolumn{3}{|c|}{$\begin{array}{l}\text { Soma das rotações das } \\
\text { cargas ao quadrado }\end{array}$} \\
\hline & & $\%$ & $\%$ & & $\%$ & $\%$ & & $\%$ & $\%$ \\
\hline & Total & Variância & Acum. & Total & Variância & Acum. & Total & Variância & Acum. \\
\hline 1 & 4,38 & 21,89 & 21,89 & 4,38 & 21,89 & 21,89 & 3,09 & 15,43 & 15,43 \\
\hline 2 & 1,82 & 9,08 & 30,97 & 1,82 & 9,08 & 30,97 & 2,07 & 10,35 & 25,77 \\
\hline 3 & 1,79 & 8,94 & 39,92 & 1,79 & 8,94 & 39,92 & 1,96 & 9,81 & 35,58 \\
\hline 4 & 1,34 & 6,68 & 46,60 & 1,34 & 6,68 & 46,60 & 1,76 & 8,79 & 44,37 \\
\hline 5 & 1,20 & 6,02 & 52,62 & 1,20 & 6,02 & 52,62 & 1,42 & 7,08 & 51,45 \\
\hline 6 & 1,05 & 5,25 & 57,87 & 1,05 & 5,25 & 57,87 & 1,23 & 6,14 & 57,60 \\
\hline 7 & 1,01 & 5,07 & 62,93 & 1,01 & 5,07 & 62,93 & 1,07 & 5,34 & 62,93 \\
\hline
\end{tabular}

Fonte: Dados da pesquisa, 2006/2007.

Um produto importante obtido a partir da rotação dos fatores é a matriz dos fatores, que contém os coeficientes utilizados para expressar as variáveis utilizadas em termos de fatores. Esses coeficientes ou cargas fatoriais representam as correlações entre os fatores e as variáveis. Coeficientes muito altos significam que o fator e a variável estão estreitamente relacionados (MALHOTRA, 2001).

De forma geral, os resultados da análise multivariada por componentes principais permitem identificar que o primeiro e o terceiro componentes representam o uso econômico da terra. O segundo componente representa as instituições de ensino, pesquisa e extensão. $\mathrm{O}$ quarto componente representa as diversidades sociais rurais. Contudo, não é o objetivo deste trabalho a caracterização dos fatores. Como discutido anteriormente, o objetivo da extração dos componentes tem a finalidade de filtrar informações relevantes para a classificação dos municípios.

\subsection{Classificação dos resultados}

Neste trabalho, o método de classificação utilizado foi o hierárquico, e o método de aglomeração escolhido foi o Método de Ward, conforme discutido anteriormente. As classificações foram dividas seguindo o seguinte raciocínio: a partir da análise de cluster dos sete primeiros eixos fatoriais (que representaram 62,93\% da variância dos dados), obtiveram-se as classificações da dimensão geral, ou seja, envolvendo todas as seis dimensões estratégicas específicas ao desenvolvimento rural sustentável, denominada, neste trabalho, como Índice de Desenvolvimento Rural Sustentável (IDRS). Na Tabela 3, apresenta-se a justificativa para partir 
da análise fatorial e não das variáveis originais, como mencionado anteriormente, é que ela pode funcionar para filtrar informação bruta, apresentando, de forma resumida, as principais características de sua estrutura.

Tabela 3 - Componentes da matriz rotacionada

\begin{tabular}{l|c|c|c|c|c|c|c}
\hline Indicador/Fator & $\mathbf{1}$ & $\mathbf{2}$ & $\mathbf{3}$ & $\mathbf{4}$ & $\mathbf{5}$ & $\mathbf{6}$ & $\mathbf{7}$ \\
\hline Área de Pastagens & 0,88 & & & & & & \\
\hline ICMS Alimentos & 0,87 & & & & & & \\
\hline Lavouras Permanentes & 0,82 & & & & & & \\
\hline VA Agropecuária & 0,61 & & 0,48 & & & & \\
\hline SENAR & & 0,84 & & & & & \\
\hline EMATER & & 0,78 & & & & & \\
\hline EPAMIG & & 0,65 & & & & & \\
\hline Área de Lavouras Temporárias & & & 0,71 & & & & \\
\hline Nível Tecnológico da Agropecuária & & & 0,65 & & & & \\
\hline Áreas Inundadas & & & 0,51 & & & & \\
\hline Cooperativa de Crédito Rural & & & 0,49 & & & & \\
\hline Pessoal Ocupado na Agropecuária & & & & 0,71 & & & \\
\hline Indice de Agricultores Familiares & & & & 0,66 & & & \\
\hline Gestão do Desenvolvimento Rural & & & & 0,55 & & & \\
\hline Área de Floresta Plantada & & & & & 0,66 & & \\
\hline Indice de Gini & & & & & 0,65 & & \\
\hline Gestão Ambiental Municipal & & & 0,40 & & 0,48 & & \\
\hline Áreas de Proteção Integral & & & & & & 0,81 & \\
\hline ÉcMS Ecológico & & & & & & 0,73 & \\
\hline
\end{tabular}

Fonte: Dados da pesquisa, 2006/2007.

O procedimento adotado separadamente para cada dimensão estratégica do desenvolvimento rural sustentável teve como referência os indicadores selecionados dentro de cada uma das seis dimensões. Nos anexos deste trabalho, serão apresentados os resultados de frequências encontradas para cada dimensão e, ao final, o resultado encontrado para o Índice de Desenvolvimento Rural Sustentável.

Tanto para o índice geral, IDRS, quanto para as seis dimensões, o método classificou os municípios em cinco categorias, que constituem os diferentes graus de combinações de aspectos relacionados ao desenvolvimento rural sustentável, sintetizados da seguinte maneira: os resultados encontrados para a Dimensão Diversidades Regionais e Sociais indicam que $56,04 \%$ dos municípios foram classificados no cluster 1 , ou seja, em condições precárias de desenvolvimento rural sustentável; $26,14 \%$ dos municípios se caracterizam por possuir condições favoráveis de desenvolvimento sustentável (cluster 4); apenas 1\% dos municípios do estado de Minas Gerais foram classificados no cluster 5, ou seja, em condições muito favoráveis de desenvolvimento sustentável.

O Quadro 1 mostra a distribuição das categorias analíticas utilizadas para classificar os municípios mineiros. A partir das análises feitas nas regiões de planejamento em todo o Estado de Minas Gerais (Triângulo Mineiro, Zona da Mata, Leste, Centro-oeste, Noroeste, Norte, Sul e a região central) é possível perceber uma predominância de condições precárias 
de desenvolvimento rural sustentável na região da Zona da Mata, além de algumas porções concentradas, localizadas na região Leste e Central de Minas Gerais.

Os resultados da classificação dos municípios para a Dimensão Direitos e Qualidade de Vida indicam que os resultados ficaram bastante concentrados, sendo 54,87\% dos municípios classificados em condições precárias de desenvolvimento rural sustentável ou condições desfavoráveis de desenvolvimento rural sustentável (cluster 1), enquanto 34\% dos municípios foram classificados em condições desfavoráveis de desenvolvimento rural sustentável (cluster 2). Em contrapartida, apenas 1,41\% dos municípios foram classificados em condições muito favoráveis de desenvolvimento sustentável (cluster 5).

\begin{tabular}{|l|l|}
\hline Cluster & \multicolumn{1}{c|}{ Categorização } \\
\hline Cluster 1 & Municípios em condições precárias de desenvolvimento rural sustentável. \\
\hline Cluster 2 & Municípios em condições desfavoráveis de desenvolvimento rural sustentável. \\
\hline Cluster 3 & Municípios em condições pouco favoráveis de desenvolvimento rural sustentável. \\
\hline Cluster 4 & Municípios em condições favoráveis de desenvolvimento rural sustentável. \\
\hline Cluster 5 & Municípios em condições muito favoráveis de desenvolvimento rural sustentável. \\
\hline
\end{tabular}

Fonte: Dados da pesquisa, 2006/2007.

cluster.

Quadro 1 - Categorização dos municípios mineiros a partir da técnica de análise de

Observa-se, ainda, uma predominância das classificações precárias ou desfavoráveis de desenvolvimento rural sustentável em quase toda totalidade do território mineiro. Aparecem, nas regiões do Triângulo Mineiro e Centro-Oeste de Minas Gerais, as condições de porções concentradas de municípios em condições pouco favoráveis de desenvolvimento rural sustentável. Este fenômeno é justificado pelo fato de que poucos municípios possuem áreas de proteção integral e, consequentemente, não recebem o repasse de ICMS Ecológico referente a esse quesito. Além disso, pequena parcela dos municípios apresenta significativa representatividade de agricultores familiares e, consequentemente, algum programa ou estrutura de apoio à produção e à comercialização de produtos agrícolas que atenda, especialmente, aos pequenos produtores rurais ou, ainda, que possua estruturas de apoio ao desenvolvimento agropecuário.

Os resultados de frequência da Dimensão Conhecimentos e Saberes demonstram que a grande maioria dos municípios foi classificada em condições precárias de desenvolvimento rural sustentável, ou seja, 93,9\% dos municípios mineiros foram classificados no cluster 1. Esse resultado é coerente, uma vez que apenas municípios polo ou pouquíssimos municípios são favorecidos pela presença de alguma instituição de ensino, pesquisa e extensão. Essa dimensão favorece esses municípios, contudo, acaba desfavorecendo municípios que, muitas vezes, apresentam boas condições de desenvolvimento desse tipo de instituições, porém estão localizados próximos a algum município que já é contemplado por alguma instituição de conhecimento e saber. Contudo, há que se levar em consideração a importância de se contemplar esse tipo de indicador nesse tipo de pesquisa.

As considerações referentes à dimensão organização social e participação política indicam um percentual acumulado de $48,65 \%$ dos municípios classificados em condições precárias, desfavoráveis ou pouco favoráveis de desenvolvimento rural sustentável. Em contrapartida, o percentual acumulado para os municípios classificados em condições favoráveis e muito favoráveis é de 51,35\%. Os resultados apresentados indicam que, em boa parte do Estado, os municípios foram classificados em condições favoráveis de desenvolvimento rural 
sustentável. Existem, contudo, na região Central, Sul, Triângulo e Norte do Estado algumas pequenas porções concentradas de municípios nas categorias precárias de desenvolvimento rural sustentável.

As frequências da dimensão organização econômica e mercados revelam que grande parte dos municípios foi classificada em condições precárias de desenvolvimento rural sustentável (cluster 1). Observa-se também uma predominância de municípios classificados em condições favoráveis de desenvolvimento rural sustentável, ou seja, 31,30\% dos municípios estão presentes no cluster 4. A análise demonstra que, em grande parte do Estado, os municípios foram classificados em condições precárias de desenvolvimento rural sustentável. Contudo, é possível afirmar que algumas pequenas porções do Norte do Estado apresentaram condições favoráveis e muito favoráveis de desenvolvimento rural sustentável.

Os resultados referentes à dimensão produção, consumo e sustentabilidade, demonstram que a distribuição de frequência dos municípios se concentrou mais nos clusters 5 (condições muito favoráveis de desenvolvimento rural sustentável), 3 (condições pouco favoráveis de desenvolvimento rural sustentável) e 2 (condições desfavoráveis de desenvolvimento rural sustentável), com percentuais de 32,59\%,27,90\% e 17,35\%, respectivamente.

Constata-se, ainda, que os municípios obtiveram classificações bastante interessantes. Foi possível observar que toda a região localizada mais ao oeste do Estado apresentou condições predominantemente desfavoráveis de desenvolvimento rural sustentável. Já na porção que abrange boa parte da região Norte e Leste do Estado, observou-se que os municípios foram classificados, predominantemente, nas classes 4 e 5, ou seja, "condições favoráveis" e "muito favoráveis" de desenvolvimento rural sustentável.

Finalmente, os resultados da análise multivariada por componentes principais, a partir da combinação de 20 indicadores, agrupados em seis dimensões, geraram o Índice de Desenvolvimento Rural Sustentável. Os resultados de frequência indicam que 75,97\% dos municípios estão classificados em condições precárias de desenvolvimento rural sustentável. Apenas $1,06 \%$ dos municípios foi classificado na categoria condições muito favoráveis de desenvolvimento rural sustentável.

\section{Considerações finais e recomendações}

As discussões teóricas e as evidências empíricas apresentadas e analisadas no decorrer deste trabalho, em torno da temática "desenvolvimento rural sustentável", tendo como temáticas integrantes "políticas públicas" e "Estado", possibilitaram a reflexão de políticas públicas voltadas ao desenvolvimento rural sustentável, vias alternativas que emergem no cenário brasileiro, enquanto contexto geral, e no cenário mineiro, enquanto contexto particular com vistas à identificação e análises mais pormenorizadas no que tange às questões ligadas ao meio rural e ao desenvolvimento sustentável.

Nesse sentido, para gerar desenvolvimento econômico sustentável, é necessário um conjunto articulado de políticas, como forma de melhorar as condições socioeconômicas de agricultores familiares e das populações tradicionais. A partir dos resultados discutidos ao longo deste trabalho, constatou-se que o resultado final do Índice de Desenvolvimento Rural Sustentável demonstra uma predominância dos municípios em condições precárias de desenvolvimento rural sustentável em grande parte do território mineiro, com exceção de algumas porções concentradas de municípios em condições desfavoráveis no que se refere a esta tipologia de desenvolvimento em parte das regiões denominadas Triângulo Mineiro e Centro-Oeste do Estado. Observaram-se também algumas porções concentradas de municípios 
em condições desfavoráveis de desenvolvimento rural sustentável no Sul de Minas. É possível perceber que poucos municípios foram classificados nas classes 4 e 5, ou seja, em condições favoráveis e muito favoráveis de desenvolvimento rural sustentável. No entanto, torna-se necessário criar as condições fundamentais que possibilitem a emergência de políticas públicas voltadas ao meio rural que dê sustentação à renda de agricultores e das populações tradicionais, por meio de mecanismos de apoio financeiro e de garantia da produção.

Contudo, torna-se indispensável a garantia de espaços para a atuação política dos agentes sociais envolvidos direta e indiretamente nas formulações de políticas públicas. Cabe às institucionalidades consolidadas na sociedade brasileira (mineira), aprofundar, ao máximo, a democratização da gestão pela participação efetiva dos agricultores familiares, da população tradicional e de suas formas de representação no âmbito local, de forma a produzir um ambiente institucional que dê amparo à implementação das políticas públicas de desenvolvimento rural sustentável. Em síntese, todas essas considerações, recomendações e possibilidades que envolvem o desenvolvimento rural sustentável serão em vão ou dificilmente obterão êxitos se o reconhecimento das formas tradicionais de manifestação e produção cultural e dos saberes locais acumulados e transmitidos de geração para geração, bem como a valorização das identidades coletivas, subjacentes às formas tradicionais de organização social, não forem significativamente levadas em consideração, já que são traços essenciais de um "mundo rural" que integra a diversidade cultural dos grupos que o conformam. Portanto, cabe, aqui, considerar que tradição e modernidade buscam novos elos na construção de projetos de desenvolvimento rural sustentável. 


\section{Referências}

AAKER, D.A. et al. Pesquisa de marketing. São Paulo: Atlas, 2001.

BARRACLOUGH, S. Land reform in developing countries: the role of the state and other actors. Genebra: United Nations Research Institute for Social Development, 1998.

BRESSER PEREIRA, L. C. Reforma do Estado e administração pública gerencial. Rio de Janeiro: FGV, 1998.

BUAINAIN, A. M. Trajetória recente da política agrícola brasileira. Campinas: Projeto FAO/036/ BRA, 1997.

BUAINAIN, A. M.; REZENDE, G. de C. Ajuste, inflação e agricultura no Brasil: a experiência dos anos oitenta. In: RAMOS, P.; REYDON, B. (Orgs.). Agropecuária e agroindústria no Brasil: ajuste, situação atual e perspectivas. Campinas: ABRA, 1995. p. 20-38.

CAVALCANTI, C. Desenvolvimento e natureza: estudos para uma sociedade sustentável. São Paulo: Cortez, 1995.

CARVALHO, M.A. Políticas públicas e competitividade da agricultura brasileira. Revista de Economia Política, São Paulo, v. 21, n. 1, p. 2-21, jan./mar. 2001.

DE JANVRY, A. Why do governments do what they do? The case of food price policy. In: JOHNSON, D.G.; SCHUH, G.E. (Orgs.). The role of markets in the world food economy. Boulder: Westview, 1983. p. 31-54.

DELGADO, N. As relações entre a macroeconomia e a política agrícola: provocações para um debate interrompido. Estudos Sociedade e Agricultura, Rio de Janeiro, n. 14, p.18-36, abr. 2000.

DELGADO, G.; CARDOSO Jr., J. C. Universalização de direitos sociais no Brasil: a previdência rural nos anos 90. In: LEITE, S.
(Org.). Políticas públicas e agricultura no Brasil. Porto Alegre: Ed. da UFRGS, 2001. p. 86-131.

FALKENSTEIN, E.; HANWECK, J. Minimizing basis risk from non-parallel shifts in the yield curve Part II: Principal Components. The Journal of Fixed Income, v. 7, n. 1, p.39-56, 1997.

FREY, K. Políticas públicas: um debate conceitual e reflexões referentes à prática da análise de políticas públicas no Brasil. Planejamento e políticas públicas, Brasília, IPEA, n. 21, p.211259, jun., 2000.

GRAZIANO DA SILVA, J. Condicionantes para um novo modelo agrário e agrícola. In: APPY, B. et al. Crise brasileira: anos oitenta e governo Collor. São Paulo: CGIL/CUT, 1993. p. 43-68.

HAIR JR. et al. Análise multivariada de dados. 5. ed. Porto Alegre: Bookman, 2005.

HELFAND, S. The political economy of agricultural policy in Brazil: decision making and influence from 1964 to 1992. Latin American

Research Review, v. 34, n. 2, p. 3-41, 1999.

HELFAND, S.M.; REZENDE, G.C. A agricultura brasileira nos anos 1990: o impacto das reformas de políticas. In: GASQUES, J.G.; CONCEIÇÃO, J.C.P.R. (Orgs.). Transformações da agricultura e políticas públicas. Brasília: Ipea, 2001. p. $247-$ 302.

HUNTINGTON, S. P. Political order in changing societies. New Haven/London: Yale University Press, 1969.

JOHNSON, R. A.; WICHERN, D. W. Applied multivariate statistical analysis. New Jersey: Prentice-Hall; A. Simon e Schuster Company Upper Saddle River, 1992.

KAGEYAMA, A.; LEONE, E. T. Uma tipologia dos municípios paulistas com base em indicadores sociodemográficos. Texto para discussão. Campinas: IE/UNICAMP, n. 66, jan. 1999.

LAMOUNIER, B. (Coord.). Determinantes políticos da política agrícola: um estudo de atores, demandas e mecanismos de decisão. Brasília: IPEA, 1994. 
LEITE, S. Padrão de financiamento, setor público e agricultura no Brasil. In: LEITE, S. (Org.).

Políticas públicas e agricultura no Brasil. Porto Alegre: Ed. da UFRGS, 2001. p. 41-87.

LEITE, S.; MEDEIROS, L. Marchas e contramarchas na política agrária. In: ROCHA, D.; BERNARDO, M. (Orgs.). A era FHC e o governo Lula: transição? Brasília: Inesc, 2004. p. 119-168.

MALHOTRA, N. K. Pesquisa de marketing: uma orientação aplicada. Porto Alegre: Bookman, 2001.

MALUF, R. Políticas agrícolas e de desenvolvimento rural e a segurança alimentar. In: LEITE, S. (Org.). Políticas públicas e agricultura no Brasil. Porto Alegre: Ed. da Universidade, 2001. p. 42-71.

MDA/CONDRAF. Diretrizes para o

desenvolvimento sustentável. Ministério do desenvolvimento agrário. DF: Brasília, 2006.

PEREIRA, A. SPSS: Guia prático e utilização. 5. ed. (Rev. Amp.) Lisboa: Silabo, 2004.

REZENDE, F. da C. Organizações e respostas institucionais a políticas de reformas do Estado: um estudo de caso na administração do executivo federal brasileiro. Revista de Sociologia e Política, Curitiba, n. 14, p. 119138, jun. 2000.

REZENDE, G. Estado, macroeconomia e agricultura no Brasil. Porto Alegre/Rio de Janeiro: Ed. da UFRGS/ IPEA, 2003.

VEIGA, J.E. Poverty alleviation through access to land: the experience of the Brazilian 'agrarian reform process'. Land Reform. Roma, FAO, 2004. (special number).

VITORINO, N. et al. Desenvolvimento e ruralidade em Portugal: uma análise empírica. Lisboa: GPPAA, 2004.

ZHANG, X.; FAN, S. Public investment and regional inequality in rural china. Washington, DC, USA: International Food Policy Research Institute (IFPRI), Development Strategy and

Governance Division, 2006.
ZEE/MMA. Zoneamento ecológico-econômico do baixo rio Paranaíba: subsídios técnicos.

Relatório final. Brasília: MMA/SDS, 2002.

ZEE-MG. Zoneamento ecológico-econômico do estado de Minas Gerais. Relatório. Lavras, MG: ZEE-MG, 2007. 